Pacific Journal of Mathematic 


\section{THEOREMS ON CESÀRO SUMMABILITY OF SERIES}

\section{S. Muкноті}

1.1. We consider the Cesaro summability, for integral orders, of the series

$$
\sum_{\nu=0}^{\infty} a_{\nu} d_{\nu}
$$

In this paper we establish equivalence theorems for the series (1.1) which are valid for a substantial class of sequences $d_{\nu}$ including $e^{-\nu}$ and $\nu^{-\delta}$. Results of this character, but not overlapping with those in this paper, were given by Hardy and Littlewood and by Andersen. Andersen's result was extended by Bosanquet and Chow, and further extended by Bosanquet.

Notation. 1.2. We write $A_{n}^{0}=A_{n}=a_{0}+a_{1}+\cdots+a_{n}$,

$$
A_{n}^{k}=A_{0}^{k-1}+A_{1}^{k-1}+\cdots+A_{n}^{k-1}
$$

and we get the identities: See Hardy [8].

$$
\begin{aligned}
& A_{n}^{k}=\sum_{\nu=0}^{n} B_{n-\nu}^{k-1} A_{\nu}, \\
& A_{n}^{k}=\sum_{\nu=0}^{n} B_{n-\nu}^{k} a_{\nu},
\end{aligned}
$$

where

$$
B_{n-\nu}^{k}=\left(\begin{array}{c}
n-\nu+k \\
k
\end{array}\right)
$$

$E_{n}^{k}=A_{n}^{k}$ when $a_{0}=1, a_{n}=0$, for $n>0$, i.e., when $A_{n}=1$, for all $n$. Hence

$$
E_{n}^{k}=\left(\begin{array}{c}
n+k \\
k
\end{array}\right) \sim \frac{n^{k}}{k !}
$$

If

$$
\frac{A_{n}^{k}}{E_{n}^{k}} \rightarrow A \text {, when } n \rightarrow \infty,
$$

or equivalently if

$$
\frac{k ! A_{n}^{k}}{n^{k}} \rightarrow A \text {, when } n \rightarrow \infty,
$$

then we say that $\sum_{n=0}^{\infty} a_{n}$ is summable $(C, k)$ to sum $A$ and we write 


$$
\sum_{n=0}^{\infty} a_{n}=A(C, k) .
$$

1.3. Statement of lemma and identiy. We write

$$
\Delta d_{n}=d_{n}-d_{n-1}, \Delta^{k} u_{n}=\Delta \Delta^{k-1} u_{n}
$$

and $\Delta^{0} u_{n}=u_{n}$.

We shall use the following well-known identity:

$$
\Delta^{k}\left(u_{n} v_{n}\right)=\sum_{\nu=0}^{k}\left(\begin{array}{l}
k \\
\nu
\end{array}\right) \Delta^{\nu} u_{n} \Delta^{k-\nu} v_{n-\nu} .
$$

Lemma A. In order that

$$
t_{m}=\sum C_{m, n} S_{n} \rightarrow S(m \rightarrow \infty), \quad(m=0,1,2, \cdots)
$$

whenever

$$
S_{n} \rightarrow S
$$$$
(n \rightarrow \infty),
$$

it is necessary and sufficient that

$$
\sum\left|C_{m, n}\right|<H,
$$

where $H$ is independent of $m$;

$$
C_{m, n} \rightarrow 0,
$$

for each $n$, when $m \rightarrow \infty$;

$$
\sum C_{m, n} \rightarrow 1 \text {, when } m \rightarrow \infty .
$$

Lemma A is mentioned by Hardy [8, Th. 2], which is due to Toeplitz [12]. Toeplitz considers only triangular transformations, in which $C_{m, n}=0$ for $n>m$. The extension to general transformations was made by Steinhaus [11].

2. Statement and proof of the theorem.

Theorem (the cases $k=1,2, \cdots)$. Suppose that $d_{n}>$ for $n \geqq 0$, and

$$
d_{n+1}^{k}=o\left(n^{k}\right) \text { as } n \rightarrow \infty,
$$

(ii) $\left(1 / B_{n}^{k}\right) \sum_{m=0}^{n} B_{m}^{k}\left|\Delta^{k}\left\{\Delta\left(1 / d_{m+k+1}\right) \sum_{\nu=m+k}^{n} B_{n-\nu}^{k-1} d_{\nu+1}\right\}\right|=O(1)$,

(4 operating on $\mathrm{m}$ ) .

Then necessary and sufficient conditions for 
(2.3) ( I ) $\quad \sum_{\nu=0}^{\infty} a_{\nu} d_{\nu}$ to be summable $(C, k)$ to $S$ are that

(2.4) (II) $\quad-\sum_{\nu=0}^{\infty} S_{\nu} \Delta d_{\nu+1}$ should be summable $(C, k)$ to $S$ and

$$
S_{n} d_{n+1}=o(1)(C, k) \text { as } n \rightarrow \infty,
$$

where

$$
S_{n}=\sum_{\nu=0}^{n} a_{\nu}
$$

Proof. We have

$$
\begin{gathered}
\sum_{\nu=0}^{n} a_{\nu} d_{\nu}=S_{n} d_{n+1}-\sum_{\nu=0}^{n} S_{\nu} \Delta d_{\nu+1} \\
C_{n}=F_{n}-G_{n}
\end{gathered}
$$

i.e.,

and hence

$$
C_{n}^{k}=F_{n}^{k}-G_{n}^{k}
$$

The sufficiency follows immediately from (2.8).

Necessity. We are given that

$$
C_{n}^{k} / B_{n}^{k} \rightarrow S \text { as } n \rightarrow \infty,
$$

and it will be enough to prove that

$$
-G_{n}^{k} / B_{n}^{k} \rightarrow S \text { as } n \rightarrow \infty .
$$

From (2.7) we have

$$
\begin{aligned}
\frac{C_{n} \Delta d_{n+1}}{d_{n+1}} & =S_{n} \Delta d_{n+1}-\frac{\Delta d_{n+1}}{d_{n+1}} G_{n}, \\
& =\frac{d_{n}\left(d_{n+1} \Delta G_{n}-G_{n} \Delta d_{n+1}\right)}{d_{n} d_{n+1}}=d_{n} \Delta\left(\frac{G_{n}}{d_{n+1}}\right) .
\end{aligned}
$$

Thus

$$
\frac{G_{n}}{d_{n+1}}=\sum_{\nu=0}^{n} \frac{C_{\nu}}{d_{\nu}} \frac{\Delta d_{\nu+1}}{d_{\nu+1}}
$$




$$
-G_{n}=d_{n+1} \sum_{\nu=0}^{n} C_{\nu} \Delta\left(1 / d_{\nu+1}\right)
$$

and hence

$$
\begin{aligned}
-G_{n}^{k} & =\sum_{\nu=0}^{n} B_{n-\nu}^{k-1} d_{\nu+1} \sum_{m=0}^{\nu} C_{m} \Delta\left(1 / d_{m+1}\right) \\
& =\sum_{m=0}^{n} C_{m} \Delta\left(1 / d_{m+1}\right) \sum_{\nu=m}^{n} B_{n-\nu}^{k-1} d_{\nu+1} \\
& =\sum_{m=0}^{n}(-1)^{k} C_{m}^{k} \Delta^{k}\left\{\Delta\left(1 / d_{m+k+1}\right) \sum_{\nu=m+k}^{n} B_{n-\nu}^{k-1} d_{\nu+1}\right\} .
\end{aligned}
$$

It follows that

$$
\begin{aligned}
-\frac{G_{n}^{k}}{B_{n}^{k}} & =\frac{1}{B_{n}^{k}} \sum_{m=0}^{n}(-1)^{k} \frac{C_{m}^{k}}{B_{m}^{k}} \cdot B_{m}^{k} \Delta^{k}\left\{\Delta\left(1 / d_{m+k+1}\right) \sum_{\nu=m+k}^{n} B_{n-\nu}^{k-1} d_{\nu+1}\right\} \\
& =\sum_{m=0}^{n} T_{m} \gamma_{n, m},
\end{aligned}
$$

where

$$
T_{m}=C_{m}^{k} / B_{m}^{k},
$$

and

$$
\gamma_{n, m}=(-1)^{k} \frac{B_{m}^{k}}{B_{n}^{k}} \Delta^{k}\left\{\Delta\left(1 / d_{m+k+1}\right) \sum_{\nu=m+k}^{n} B_{n-\nu}^{k-1} d_{\nu+1}\right\}
$$

Hence

$$
\text { (i ) } \sum_{m=0}^{n}\left|\gamma_{n, m}\right|=\left(1 / B_{n}^{k}\right) \sum_{m=0}^{n} B_{m}^{k}\left|\Delta^{k}\left\{\Delta\left(1 / d_{m+k+1}\right) \sum_{\nu=m+k}^{n} B_{n-\nu}^{k-1} d_{\nu+1}\right\}\right|<H \text {, }
$$

by hypothesis (ii).

Now, from (2.16), we have, for each $m$

$$
\begin{aligned}
\gamma_{n, m}= & (-1)^{k}\left(B_{m}^{k} / B_{n}^{k}\right)\left[\Delta^{k+1}\left(1 / d_{m+k+1}\right) \sum_{\nu=m+k}^{n} B_{n-\nu}^{k-1} d_{\nu+1}\right. \\
& +\alpha_{k} \Delta^{k}\left(1 / d_{m+k}\right)\left(\begin{array}{c}
n-m \\
k-1
\end{array}\right) d_{m+k}+\cdots \\
& +\alpha_{1}^{1} \Delta\left(1 / d_{m+1}\right)\left(\begin{array}{c}
n-m \\
k-1
\end{array}\right) \Delta^{k-1} d_{m+k} \\
& \left.+\cdots+\alpha_{k-1}^{1} \Delta\left(1 / d_{m+1}\right) \Delta^{k-1}\left(\begin{array}{c}
n-m \\
k-1
\end{array}\right) d_{m+1}\right],
\end{aligned}
$$

( $\alpha$ various constants)

using the identity (1.9).

Then from (2.18) it follows that for each $m$ 


$$
\gamma_{n, m}=A_{n, m}+O\left(\frac{1}{n}\right)=A_{n, m}+o(1), \text { as } n \rightarrow \infty,
$$

where

$$
\left|A_{n, m}\right|<\frac{k !}{n^{k}} B_{m}^{k}\left|\Delta^{k+1}\left(1 / d_{m+k+1}\right)\right| \sum_{\nu=0}^{n} B_{n-\nu}^{k-1} d_{\nu+1}<\frac{K}{n^{k}} d_{n+1}^{k}=o(1)
$$

for each $m$, as $n \rightarrow \infty$, by hypothesis (i).

Hence it follows from (2.19)-(2.20) that

$$
\gamma_{n, m} \rightarrow 0 \text { for each } m \text {, as } n \rightarrow \infty \text {. }
$$

Let us take

$$
a_{0}=1, a_{\nu}=0, \text { for } \nu \geqq 1 \text {, and } d_{0}=1
$$

in

$$
C_{n}=\sum_{\nu=0}^{n} a_{\nu} d_{\nu} .
$$

Then we have, for $n \geqq 0, C_{n}=1$, and hence

$$
C_{n}^{k} / B_{n}^{k}=1 \text {. }
$$

Next, since $C_{\nu}=1, d_{0}=1$, we obtain from (2.12)

$$
-G_{n}=d_{n+1} \sum_{\nu=0}^{n} \Delta\left(1 / d_{\nu+1}\right)=1-d_{n+1}
$$

and hence

$$
-G_{n}^{k} / B_{n}^{k}=1-d_{n+1}^{k} / B_{n}^{k} \rightarrow 1 \text { as } n \rightarrow \infty,
$$

by hypothesis (i).

But this implies, from (2.14)-(2.15), that

$$
-G_{n}^{k} / B_{n}^{k}=\sum_{m=0}^{n} \gamma_{n, m} \rightarrow 1 \text { as } n \rightarrow \infty .
$$

It follows that conditions (i), (ii) and (iii) of Lemma $\mathrm{A}$ are satisfied, and hence

$$
-G_{n}^{k} / B_{n}^{k} \rightarrow S \text { as } n \rightarrow \infty \text {. }
$$

Note. Hypotheses (i) and (ii) of the Theorem are necessary. For suppose that $-G_{n}^{k} / B_{n}^{k} \rightarrow S$ as $n \rightarrow \infty$, whenever $C_{n}^{k} / B_{n}^{k} \rightarrow S$ as $n \rightarrow \infty$.

Then from (2.14)-(2.16), condition (i) of Lemma A must hold, but this implies (2.17) and hence hypothesis (ii) of Theorem 2.

Next, let us choose $C_{n}$ so that (2.23) holds. Then (2.3) holds, with $S=1$, and hence (2.24) holds. Hence it follows that $d_{n+1}^{k} / B_{n}^{k}=$ 
$o(1)$ as $n \rightarrow \infty$, and this implies hypothesis (i) of the theorem.

Further the summability $(C, k)$ of $(2.4)$ can be improved to the summability $(C, k-1)$, by the following Lemma.

Lemma B. If $d_{n}$ is monotonically decreasing and

$$
\begin{aligned}
& n^{j} \Delta^{j} d_{n+1}=O\left(d_{n+1}\right), \\
& n^{j} \Delta^{j} t_{n+1}=O\left(t_{n+1}\right),
\end{aligned}
$$

for $j=1,2, \cdots, k+1$, where

$$
t_{n}=1 / d_{n},
$$

then

$$
\text { (iii) } S_{n} d_{n+1}=o(1)(C, k) \Rightarrow n S_{n} \Delta d_{n+1}=o(1)(C, k) \text {. }
$$

Proof. We have

$$
H_{n}=S_{n} d_{n+1}=o(1)(C, k) .
$$

We will prove that

$$
H_{n} g_{n}=o(1)(C, k),
$$

where

$$
g_{n}=\frac{n \Delta d_{n+1}}{d_{n+1}}=n \Delta d_{n+1} t_{n+1} .
$$

By a theorem of Bosanquet [6, Th. 1], which is an extension of another theorem of Bosanquet [4, Lemma 1], it will be enough to prove that

$$
\Delta^{j} g_{n}=O\left(n^{-j}\right), \quad j=0,1, \cdots k-1,
$$

and

$$
\sum_{\nu=1}^{n} \nu^{k}\left|\Delta^{k} g_{\nu}\right|=O(n)
$$

Now

$$
g_{n}=n \Delta d_{n+1} t_{n+1} \leqq K d_{n+1} t_{n+1} \leqq K,
$$

by (2.44).

Next, using the identity (1.9), we have

$$
\begin{aligned}
& \left|\Delta^{k-1} g_{n}\right|=\alpha_{1} n\left|\Delta d_{n+1}\right|\left|\Delta^{k-1} t_{n+1}\right|+\cdots+\alpha_{k-1} n\left|\Delta^{k} d_{n+1}\right| t_{n+1-k+1} \\
& +\alpha^{1}\left|\Delta d_{n+1}\right|\left|\Delta^{k-2} t_{n+1}\right|+\cdots+\alpha^{k-2}\left|\Delta^{k-1} d_{n+1}\right| t_{n-1-k+2} \\
& \leqq K / n^{k-1} \text {. } \\
& \text { ( } \alpha \text { various constant) }
\end{aligned}
$$


The other conditions in (2.34) are easily obtained similarly, but it is well known that the inequalities for $j=0$ and $k-1$ imply those for $j=1,2, \cdots, k-2$ : See Hardy and Littlewood [9].

Next we have

$$
\begin{aligned}
\left|\Delta^{k} g_{n}\right| \leqq & \alpha_{1} n\left|\Delta d_{n+1}\right|\left|\Delta^{k} t_{n+1}\right|+\cdots+\alpha_{k} n\left|\Delta^{k+1} d_{n+1}\right| t_{n+1-k} \\
& +\alpha^{1}\left|\Delta d_{n+1}\right|\left|\Delta^{k-1} t_{n+1}\right|+\cdots+\alpha^{k-1}\left|\Delta^{k} d_{n+1}\right| t_{n+1-k+1} \\
\leqq & K / n^{k}
\end{aligned}
$$

Hence

$$
\sum_{\nu=1}^{n} \nu^{k}\left|\Delta^{k} g_{\nu}\right| \leqq \sum_{\nu=1}^{n} \nu^{k} \frac{K}{\nu^{k}}<K n
$$

and this completes the proof the lemma.

Next we will consider the case $k=0$.

Now we have

$$
n S_{n} \Delta d_{n+1} \leqq K d_{n+1} S_{n}
$$

by (2.27), and since

$$
S_{n} d_{n+1}=o(1) \text { as } n \rightarrow \infty,
$$

it follows that

$$
n S_{n} \Delta d_{n+1}=o(1) \text { as } n \rightarrow \infty
$$

Next since

$$
\sum_{\nu=0}^{\infty} S_{\nu} \Delta d_{\nu+1}
$$

is convergent, it follows from the definition that (2.42) is summable $(C,-1)$.

In conclusion I wish to acknowledge my debts of gratitude to Prof. L. S. Bosanquet for suggesting the problem to me and for his valuable guidance and comments throughout the course of my work. I also appreciate several comments made by Mr. M. C. Austin and wish to record my appreciation of several suggestions for improvement made by Prof. D. Borwein.

\section{REFERENCES}

1. A. F. Andersen, Comparison theorems in the theory of Cesàro summability, Proc. London Math. Soc. (2) 27 (1928), 39-71. 
2. L. S. Bosanquet, Note on the Bohr-Hardy theorem, J. London Math. Soc. 17 (1942), 168-173.

3. Note on convergence and summability factors, J. London Math. Soc. 20 (1945), 39-48.

4. - On convergence and summability factors in a Drichlet series, J. London Math. Soc. 23 (1948), 35-38.

$5 . \quad$ An extension of a theorem of Andersen, J. London Math. Soc. 25 (1950), $72-80$.

6. - On convergence and summability factors in a sequence, Mathematika 1 (1954), 24-44.

7. L. S. Bosanquet and H. C. Chow, Some analogues of a theorem of Andersen, J. London Math. Soc. 16 (1941), 42-48.

8. G. H. Hardy, Divergent Series, Oxford, 1949.

9. G. H. Hardy and J. E. Littlewood, Proc. London Math. Soc. (2) 11 (1913), 411-478. 10. , A theorem in the theory of summable divergent series, J. London Math. Soc. (2) 27 (1928), 327-348.

11. Steinhaus, Prace Matematyczno-fizyczne (Warsaw) 22 (1911), 121-134.

12. Toeplitz, Prace Matematyczno-fizyczne 113-119.

Received January 12, 1968, and in revised form January 29, 1969.

Indian Institute of TeChNology

NeW DelHI 


\section{PACIFIC JOURNAL OF MATHEMATICS}

\section{EDITORS}

H. SAMelson

Stanford University

Stanford, California 94305

\section{Richard PIERCE}

University of Washington

Seattle, Washington 98105
J. DugundjI

Department of Mathematics

University of Southern California

Los Angeles, California 90007

BASIL GoRDON*

University of California

Los Angeles, California 90024

\section{ASSOCIATE EDITORS}
E. F. BECKENBACH
B. H. NeumanN
F. WOLE
K. YosHIDA

\section{SUPPORTING INSTITUTIONS}

UNIVERSITY OF BRITISH COLUMBIA

CALIFORNIA INSTITUTE OF TECHNOLOGY

UNIVERSITY OF CALIFORNIA

MONTANA STATE UNIVERSITY

UNIVERSITY OF NEVADA

NEW MEXICO STATE UNIVERSITY

OREGON STATE UNIVERSITY

UNIVERSITY OF OREGON

OSAKA UNIVERSITY

UNIVERSITY OF SOUTHERN CALIFORNIA

\author{
STANFORD UNIVERSITY \\ UNIVERSITY OF TOKYO \\ UNIVERSITY OF UTAH \\ WASHINGTON STATE UNIVERSITY \\ UNIVERSITY OF WASHINGTON \\ * * * * \\ AMERICAN MATHEMATICAL SOCIETY \\ CHEVRON RESEARCH CORPORATION \\ TRW SYSTEMS \\ NAVAL WEAPONS CENTER
}

The Supporting Institutions listed above contribute to the cost of publication of this Journal, but they are not owners or publishers and have no responsibility for its content or policies.

Mathematical papers intended for publication in the Pacific Journal of Mathematics should be in typed form or offset-reproduced, (not dittoed), double spaced with large margins. Underline Greek letters in red, German in green, and script in blue. The first paragraph or two must be capable of being used separately as a synopsis of the entire paper. The editorial "we" must not be used in the synopsis, and items of the bibliography should not be cited there unless absolutely necessary, in which case they must be identified by author and Journal, rather than by item number. Manuscripts, in duplicate if possible, may be sent to any one of the four editors. Please classify according to the scheme of Math. Rev. 36, 1539-1546. All other communications to the editors should be addressed to the managing editor, Richard Arens, University of California, Los Angeles, California, 90024.

50 reprints are provided free for each article; additional copies may be obtained at cost in multiples of 50 .

The Pacific Journal of Mathematics is published monthly. Effective with Volume 16 the price per volume (3 numbers) is $\$ 8.00$; single issues, $\$ 3.00$. Special price for current issues to individual faculty members of supporting institutions and to individual members of the American Mathematical Society: $\$ 4.00$ per volume; single issues $\$ 1.50$. Back numbers are available.

Subscriptions, orders for back numbers, and changes of address should be sent to Pacific Journal of Mathematics, 103 Highland Boulevard, Berkeley, California, 94708.

PUBLISHED BY PACIFIC JOURNAL OF MATHEMATICS, A NON-PROFIT CORPORATION

Printed at Kokusai Bunken Insatsusha (International Academic Printing Co., Ltd.), 7-17, Fujimi 2-chome, Chiyoda-ku, Tokyo, Japan.

* Acting Managing Editor. 


\section{Pacific Journal of Mathematics}

\section{Vol. 33, No. $2 \quad$ April, 1970}

Raymond Balbes and Alfred Horn, Projective distributive lattices ....... 273

John Findley Berglund, On extending almost periodic functions ......... 281

Günter Krause, Admissible modules and a characterization of reduced left

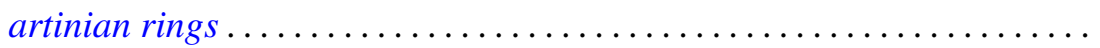

Edward Milton Landesman and Alan Cecil Lazer, Linear eigenvalues and a nonlinear boundary value problem ....................... 311

Anthony To-Ming Lau, Extremely amenable algebras ............... 329

Aldo Joram Lazar, Sections and subsets of simplexes .............. 337

Vincent Mancuso, Mesocompactness and related properties ............. 345

Edwin Leroy Marsden, Jr., The commutator and solvability in a generalized orthomodular lattice .................................. 357

Shozo Matsuura, Bergman kernel functions and the three types of canonical domains.......................................... 363

S. Mukhoti, Theorems on Cesàro summability of series .............. 385

Ngô Van Quê, Classes de Chern et théorème de Gauss-Bonnet ........... 393

Ralph Tyrrell Rockafellar, Generalized Hamiltonian equations for convex problems of Lagrange ................................ 411

Ken iti Sato, On dispersive operators in Banach lattices ............. 429

Charles Andrew Swanson, Comparison theorems for elliptic differential

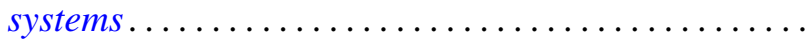

John Griggs Thompson, Nonsolvable finite groups all of whose local subgroups are solvable. II

David J. Winter, Cartan subalgebras of a Lie algebra and its ideals ... 